\title{
Diagnóstico de disposições irregulares de resíduos de construção e demolição (RCD) em Frederico Westphalen-RS
}

Com a intensificação da geração e dos problemas ambientais causados pelas disposições irregulares dos resíduos de construção e demolição nos municípios brasileiros, as administrações públicas vêm buscando formas de controlar e amenizar esses agravantes. Neste sentido, este trabalho teve a finalidade de apresentar um diagnóstico da situação atual dos RCD dispostos inadequadamente no município de Frederico Westphalen, através do levantamento de áreas de descartes clandestinos. Foram encontradas 46 áreas com despejo clandestino, grande parte são de pequeno porte e apresentaram-se, após as três vistorias realizadas, regularizadas, ativas ou inativas. Em virtude da grande incidência de áreas que ainda não foram regularizadas, $34,8 \%$ do total, ficou evidente a falta controle efetivo dessas disposições irregulares, reafirmando a ideia de que existe a necessidade de implementar um plano municipal de gerenciamento para essa classe de resíduos, caracterizando os depósitos como áreas clandestinas de RCD. Houve também o levantamento de inúmeros impactos ambientais, dentre eles, interrupção parcial de logradouro e calçamento público, presença de outros tipos de resíduos, poluição e contaminação de áreas de proteção permanente. Os dados deste trabalho podem servir como instrumento de auxílio aos órgãos públicos para o desenvolvimento de ações e diretrizes de fiscalização nessas áreas, a fim de um melhor gerenciamento desses resíduos.

Palavras-chave: Resíduos de Construção e Demolição; Gestão de Resíduos; Impactos Ambientais.

\section{Evaluation of irregular construction and demolition waste (CDW) disposal in Frederico Westphalen - RS}

\begin{abstract}
From the intensification of generation and the environmental problems caused by the irregular provisions of construction and demolition waste in Brazilian municipalities, public administrations have been looking for ways to control and soften these aggravating factors. In this sense, this work had the purpose of presenting a diagnosis of the current situation of the RCDs inadequately disposed in the municipality of Frederico Westphalen, through the survey of areas of clandestine discards. A total of 46 areas were found with clandestine eviction, most of which are of small size and, after the three inspections, were regularized, active or inactive. Due to the large incidence of areas that have not yet been regularized (34.8\%) it was evident the lack of effective control of these irregular dispositions, reaffirming the idea that there is a need to implement a municipal management plan for this class of waste, characterizing the deposits as clandestine RCD areas. There were also numerous environmental impacts, among them, partial interruption of street and public pavement, presence of other types of waste, pollution and contamination of permanent protection areas. This data collection can serve as an aid to public agencies for the development of actions and supervision guidelines in these areas, in order to better manage these wastes.
\end{abstract}

Keywords: Construction and Demolition Waste; Waste Management; Environmental Impacts.

Topic: Engenharia Sanitária

Reviewed anonymously in the process of blind peer.

Raphael Corrêa Medeiros

Universidade de São Paulo, Brasil

http://lattes.cnpq.br/2977594460581447

medeiroscg@yahoo.com.br

Eduardo Ruwer Patatt

Universidade Federal de Santa Maria, Brasil

http://lattes.cnpq.br/1030070971160889

edupatatt@yahoo.com.br

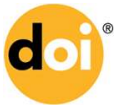

DOI: $10.6008 / S P C 2179-6858.2017 .003 .0011$
Received: 27/01/2017

Approved: 28/04/2017
Referencing this:

MEDEIROS, R. C.; PATATT, E. R.. Diagnóstico de disposições irregulares de resíduos de construção e demolição (RCD) em Frederico Westphalen-RS. Revista Ibero-Americana de Ciências Ambientais, v.8, n.3, p.112-122, 2017. DOI: http://doi.org/10.6008/SPC2179$\underline{6858.2017 .003 .0011}$ 


\section{INTRODUÇÃO}

Os Resíduos de Construção e Demolição (RCDs) são provenientes de inúmeras atividades, desde a construção, manutenção e demolição de prédios e infraestrutura civil (SILVA, 2014; DOMíNGUEZ et al., 2016). De acordo com a ABRELPE (2015), foram coletados pelos municípios brasileiros, aproximadamente $45 \mathrm{mi}$ de toneladas de RCDs, os quais podem ser apenas resíduos coletados que foram lançados ou dispostos de maneira irregular em logradouros públicos.

Segundo Santos (2008) e Oliveira et al. (2011), geram-se, no Brasil, de 400 a $700 \mathrm{Kg} / \mathrm{hab}^{-1} / \mathrm{ano}^{-1} \mathrm{de}$ RCDs, variando de acordo com a cidade, estado, em vista do tamanho populacional, nível econômico, época do ano, ano da obra, técnica utilizada na demolição, entre outros fatores. A ABRELPE (2015) relatou uma média de 0,605 kg/hab ${ }^{-1} / \mathrm{dia}^{-1}$ de RCDs, variando entre as macrorregiões brasileiras, de 0,271 a 0,901 kg/hab1/dia-1. A Resolução CONAMA 307 de 2002 define RCDs ou RCCs (resíduos de construção civil), como: “os provenientes de construções, reformas, reparos e demolições de obras de construção civil, e resultantes da preparação e escavação de terrenos [...], comumente chamados de entulhos de obras, caliça ou metralha".

Esses resíduos causam impactos econômicos, em razão de a indústria ligada à construção civil ser uma das mais importantes para a economia mundial, vindo a gerar quantidades enormes de resíduos (OSSA et al., 2016; DOMÍNGUEZ et al., 2016), além do custo no tratamento e disposição, gasto público com limpeza urbana, desobstrução de ruas e calçadas (ARAÚJO et al., 2007). Dentre os impactos ambientais, podem ser citados: o assoreamento de rios, entupimentos de bueiros, contaminação do solo, da água, ar, quase sempre relacionados ao mau condicionamento. Há ainda impactos sociais, pois o acúmulo de RCD se dá, de acordo com Dahlbo et al. (2015), principalmente, em locais afastados (terrenos em periferias e bairros mais pobres); bem como as incomodidades e riscos à saúde de pedestres e moradores (ARAÚJO et al., 2007).

Os RCDs estão inseridos, de acordo com a Norma ABNT 10004 de 2004, na classe B-II (inertes) e possuem em sua composição: madeira, materiais betuminoso, plásticos, papéis, concreto, cerâmica, materiais metálicos, entre outros materiais utilizados nas obras. No Brasil, os RCDs são compostos, prioritariamente, por concreto, argamassa, alvenaria e revestimento cerâmico (SANTOS, 2007; SANTOS, 2008).

No entanto, Lima et al. (2013) citam que a diversidade de resíduos, que acabam por compor os RCD, poderia ser classificada como Classe A, B, C e até mesmo D (resíduos perigosos), de acordo com a CONAM 307 de 2002, como as embalagens de tinta, solvente e amianto. Ling et al. (2013) e Dahlbo et al. (2015) constatam que a ideia base para melhorar a gestão ambiental e econômica de RCD seria a reciclagem, cujos impactos positivos são: menor consumo de recursos naturais; menor impacto ambiental; menor gasto energético, recuperação de materiais (plástico, metal, agregados, madeira, cobre, alumínio, ferro, etc.); geração de empregos; diminuição de problemas sociais, com a criação de empregos.

A Resolução CONAMA 307, de 2002, estabeleceu diretrizes, critérios e procedimentos para a gestão dos resíduos da construção civil, a fim de amenizar os impactos ambientais. A legislação também descreve a necessidade de se implementar a gestão de resíduos da construção civil, de um Plano Integrado de 
Gerenciamento, a ser elaborado pelos municípios e pelo Distrito Federal. Segundo Miranda et al. (2009), após essa lei, houve aumento expressivo do número de usinas de reciclagem da fração classe A no país.

Angulo et al. (2011) citam a Política Nacional de Resíduos Sólidos, Lei n 12.305 de 2010, que instiga à Educação Ambiental do cidadão (gerador), pois os autores relataram que 91\% dos RCD estudados são de Classe A, portanto recicláveis. Entretanto, os mesmos autores relatam que as disposições irregulares de RCD se tornaram uma realidade em todo o país, devido à falta de gerenciamento. Em estudo realizado por Oliveira et al. (2011), em Fortaleza/CE, 65\% do total de RCD eram passíveis de reciclagem.

Nesse contexto, para o gerenciamento adequado e a maximização da reutilização e reciclagem dos $R C D$, o levantamento de indicadores de qualidade e quantidade, através da caracterização desses resíduos sólidos nos municípios é indispensável, devido aos grandes volumes gerados e a heterogeneidade dos mesmos (CARNEIRO et al., 2001). Ressalta-se que a elaboração de planos de gerenciamento de resíduos sólidos necessita, prioritariamente, do diagnóstico a fim de identificar e quantificar a geração, de grande valor dentro de uma visão da gestão (ANGULO et al., 2011). Neste contexto, o objetivo deste trabalho foi realizar o levantamento de áreas clandestinas de depósitos de RCD no município de Frederico Westphalen RS e seus possíveis impactos ambientais.

\section{METODOLOGIA}

\section{Área de Estudo}

De acordo com IBGE (2016), o município de Frederico Westphalen está localizado na região do Médio Alto Uruguai, no Noroeste do Estado do Rio Grande do Sul, e possui uma população estimada de 30.251 habitantes, mostrando um crescimento populacional acima de $6 \%$, o qual pode potencializar a geração de RCD. O município é dividido em três distritos, mas o estudo teve abrangência apenas no perímetro urbano do distrito sede.

\section{Levantamento das áreas de disposição irregular dos RCDs}

Os dados referentes às disposições irregulares dos RCDs foram obtidos através de vistorias pelo distrito sede de Frederico Westphalen. As informações necessárias para o levantamento inicial da situação dos RCD no distrito contemplam a medição aproximada do volume de resíduos de cada área irregular encontrada. Além disso, foi enumerada a quantidade de pilhas de resíduos existentes, também com o intuito de relacionar à quantidade de resíduos contidos no local.

Desta forma, na questão quantitativa, foram considerados três parâmetros de classificação, seguindo metodologia sugerida por Córdoba (2010): Área de pequeno porte, considerando-se volumes de até $10 \mathrm{~m}^{3}$; Área de médio porte, no qual se enquadram volumes entre $10 \mathrm{~m}^{3}$ e $100 \mathrm{~m}^{3}$; e Área de grande porte, que engloba as áreas acima de $100 \mathrm{~m}^{3}$. Foi realizada também caracterização fotográfica in loco. Além disto, foram coletadas fotos aéreas, via satélite, dos locais irregulares, que demonstram a localização dos mesmos no perímetro urbano considerado, a fim de facilitar a posterior identificação desses locais. 


\section{Acompanhamento das áreas de disposição irregular encontradas}

Após verificação inicial do número de áreas e suas características, ocorrida entre os meses de maio e agosto de 2014, foram realizadas três vistorias, com periodicidade quinzenal, nos meses de setembro e outubro de 2014. O intuito foi avaliar a atividade das áreas e classificá-las como áreas de depósito clandestino ou provisório, na intenção de levantar e demostrar que alguns locais, geralmente, são usados somente como descarte provisório dos resíduos para posterior retirada e outros são utilizados clandestinamente para a disposição final. Neste aspecto, nas vistorias, foi verificada da situação atual das áreas, de acordo com a metodologia sugerida por Córdoba (2010), sendo classificadas como:

Áreas 'ativas': aquelas que continuaram recebendo resíduos, ou mesmo as áreas em que anteriormente os resíduos tenham sido removidos do local e após continuaram a receber depósitos, considerando os intervalos entre as datas das visitas;

Áreas 'inativas': locais que não mudaram sua forma e tamanho, desde a primeira visita, permanecendo iguais ao longo das três vistorias; $\mathrm{e}$

Áreas 'regularizadas': aquelas em que havia lançamento clandestino de resíduos e os mesmos foram removidos do local nos intervalos entre as visitas.

\section{Mapeamento das áreas de disposição irregular}

Neste aspecto, os dados recolhidos foram organizados em quadros, tabelas e mapas (figuras), com vistas à criação de um banco de dados. O manejo dos dados nos mapas e marcações dos pontos foi realizado no programa Quantum GIS ${ }^{\circledR}$, através de seus complementos como Google Streets Layer ${ }^{\circledR}$ e Google Hybrid Layer $^{\circledR}$.

\section{RESULTADOS E DISCUSSÃO}

A procura inicial das áreas de disposição de RCC no distrito sede, zona urbana de Frederico Westphalen, resultou em 46 áreas irregulares. Destas, constatou-se a existência de 24 áreas de pequeno porte (52,2\%), 17 (37\%) áreas enquadradas como porte médio e 5 áreas de porte grande (10,8\%), maioria em bairros residenciais. Esses resultados são próximos aos de Córdoba (2010), que relatou um aumento do número de áreas de descarte clandestino, também em regiões periféricas, no município de São Carlos/SP.

Para análise das mudanças ocorridas nestas áreas irregulares, foram feitas três novas visitas nas áreas. As mudanças observadas entre as visitas podem estar relacionadas com a regularização da área, que compreende a retirada dos resíduos do local, o aumento do volume de resíduos na área e a não regularização, ou seja, a não retirada dos resíduos do local.

Após cada vistoria foi gerado um mapa com base na vistoria anterior, possibilitando a percepção das mudanças ocorridas nas áreas nos períodos entre as vistorias. Estas mudanças estão demonstradas na sequência dos três mapas (figuras 1, 2 e 3), de acordo com a legenda, que é caracterizada por cores: Cor Vermelha, utilizado para identificar áreas inativas; Cor Amarela, para áreas cujos resíduos foram retirados (áreas regularizadas); e Cor Verde, para áreas ativas. Na primeira vistoria, 25 áreas estavam inativas (54,4\%), 7 áreas ativas (15,2\%) e 14 áreas regularizadas (30,4\%), cuja distribuição, no município, pode ser visualizada 
na figura 1. Na segunda vistoria, ocorreram algumas mudanças em relação às áreas visitadas primeiramente, como demonstra a figura 2.

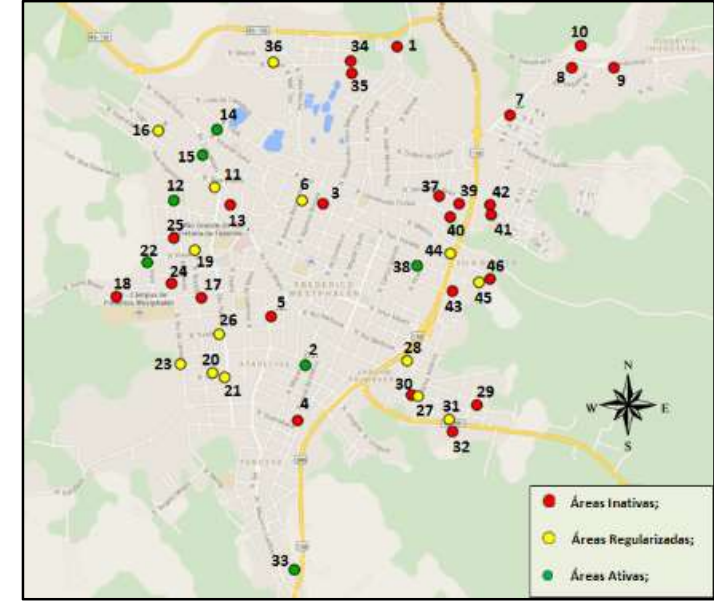

Figura 1: Mapa gerado após a primeira vistoria das áreas de disposição irregular de RCD.

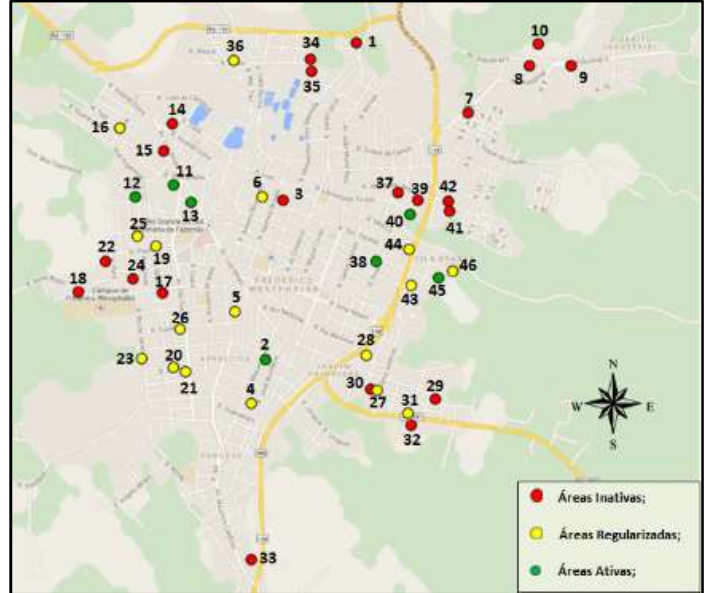

Figura 2: Mapa gerado após a segunda vistoria das áreas de disposição irregular de RCD.

Os dados obtidos da situação da primeira e da segunda vistoria mostram que houve várias mudanças em relação às atividades nas áreas. Os números quantitativos das áreas e suas respectivas atividades regularizadas com disposição de RCD em Frederico Westphalen/RS podem ser observadas no quadro 1. Lembra-se que As áreas regularizadas não podem passar para um estado Inativo, pois não contem mais resíduos no local.

Quadro 1: Quantitativo das áreas inativas, ativas e regularizadas com disposição de RCD em Frederico Westphalen/RS.

\begin{tabular}{|c|c|c|c|}
\hline Situação na 1a vistoria & Situação na 2a vistoria & Quantidade de áreas irregulares & \% \\
\hline Inativo & Ativo & 2 & 4,3 \\
\hline Inativo & Inativo & 18 & 39,1 \\
\hline Inativo & Regularizado & 5 & 10,9 \\
\hline Ativo & Ativo & 3 & 6,5 \\
\hline Ativo & Inativo & 4 & 8,70 \\
\hline Ativo & Regularizado & 0 & 0 \\
\hline Regularizado & Regularizado & 12 & 26,1 \\
\hline Regularizado & Inativo & $*$ & - \\
\hline Regularizado & Ativo & 2 & 4,4 \\
\hline
\end{tabular}

A partir da análise do quadro 1, mostra-se pouco avanço no lançamento clandestino de resíduos. A predominância de áreas inativas continua alta $(39,1 \%)$, não havendo vestígios de atividade nas mesmas, o que prova que nem o Poder Público, nem o gerador dos resíduos agiu em relação aos depósitos irregulares. O ideal é que essas áreas já tivessem sido regularizadas como se vê no item inativo/regularizado com um percentual de 10,9\%. Outro aspecto importante observado é que $26,1 \%$ das áreas em que os resíduos haviam sido retirados (áreas regularizadas) continuaram sem receber novos depósitos, contrariando o que espera de a população continuar depositando irregularmente os resíduos, pelo fato de estar acostumada aos descartes nesses locais. No entanto, esse aspecto mencionado foi verificado em 4,4\% das áreas regularizadas, as quais voltaram para a condição de áreas ativas. 


\section{Mudanças ocorridas da segunda para a terceira vistoria}

A figura 3, gerada após a última visita, aponta 9 áreas (19,6\%) continuaram ativas (pontos verdes), recebendo resíduos durante o tempo de estudo. Foi constatado que 16 áreas (34,8\%) estavam inativas, durante o período não foram regularizadas e ainda possuem resíduos dispostos inadequadamente, porém, não estão recebendo mais contribuições, e 21 áreas (45,6\%) foram regularizadas. Neste aspecto, de modo geral a população provavelmente dispõe inadequadamente seus resíduos, mas quando a obra é concluída realizam a limpeza dos entornos, destinando seus resíduos de alguma forma, seja adequada ou inadequadamente, caracterizando as áreas como de depósitos provisórios.

Em virtude da grande incidência de áreas que ainda não foram regularizadas, 34,8\% do total, fica evidente de que ainda não há um controle efetivo dessas disposições irregulares, reafirmando a ideia de que existe a necessidade de implementação de um plano municipal de gerenciamento para essa classe de resíduos, e caracterizando os depósitos como áreas clandestinas de RCD. O ponto positivo é que entre a primeira e a última visita ocorreu um aumento das áreas regularizadas, que passaram de 30,4\% na primeira visita para 45,6\% na última. Resta salientar ainda que quase a totalidade das áreas de disposição irregulares se situava em bairros residenciais. No centro da cidade também havia obras civis, porém sempre com a presença de caçambas para aporte dos RCD.

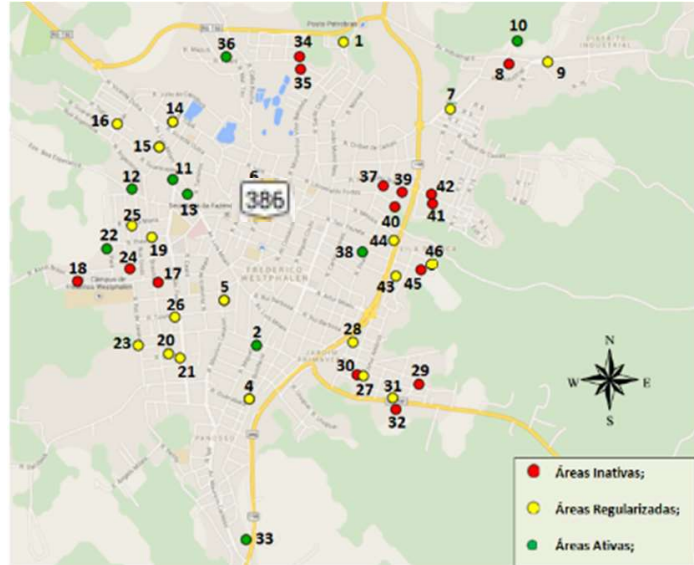

Figura 3: Mapa gerado após a terceira vistoria das áreas de disposição irregular de RCD.

As mudanças percebidas da segunda para a terceira vistoria apontam que $6,5 \%$ das áreas inativas voltaram a ficar ativas, demonstrando de que há poucas áreas ainda recebendo resíduos. O índice das áreas que continuaram inativas ficou em $28,3 \%$, confirmando o não recolhimento efetivo destes resíduos na área da pesquisa.

A incidência de áreas regularizadas que passaram para a condição de áreas ativas continua baixa $(2,1 \%)$, um fato positivo para a cidade, porque elas não estão se tornando áreas de deposito irregular contínuas, em que mesmo com a remoção dos resíduos, o local continua recebendo contribuições irregulares. O quadro 2 compara os dados da situação encontrada na segunda vistoria e para a situação encontrada na terceira vistoria. Relembra-se que As áreas regularizadas não podem passar para um estado Inativo, pois não contem mais resíduos no local. 
Quadro 2: Avaliação comparativas da situação das áreas que recebem RCD no município de Frederico Westphalen/RS.

\begin{tabular}{|c|c|c|c|}
\hline Situação na 2a vistoria & Situação na 3a vistoria & Quantidade de áreas irregulares & $\%$ \\
\hline Inativo & Ativo & 3 & 6,5 \\
\hline Inativo & Inativo & 13 & 28,3 \\
\hline Inativo & Regularizado & 6 & 13,0 \\
\hline Ativo & Ativo & 5 & 10,9 \\
\hline Ativo & Inativo & 2 & 4,4 \\
\hline Ativo & Regularizado & 0 & 0 \\
\hline Regularizado & Regularizado & 16 & 34,8 \\
\hline Regularizado & Inativo & $*$ & - \\
\hline Regularizado & Ativo & 1 & 2,1 \\
\hline
\end{tabular}

\section{Impactos ambientais ocasionados pelas áreas irregulares}

As visitas realizadas mostraram também a recorrente presença de outros tipos de resíduos misturados com os RCD. De acordo com Pinto e Gonzales (2005) e Santos (2007), as disposições descontroladas de RCD provocam uma atração para o lançamento clandestino de outros tipos de resíduos, os quais podem servir de abrigo e disponibilizar alimento para diversos vetores de doenças. Um exemplo disso foi identificado na área 36, a qual apresentou diversos tipos de resíduos, como pode ser visualizado na figura 4.

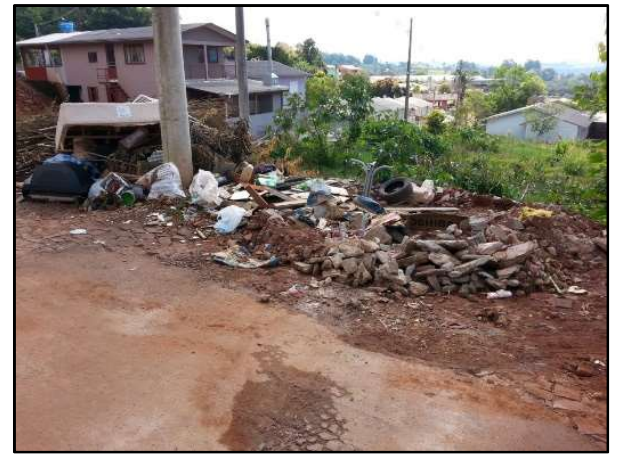

Figura 4: Acúmulo de outras classes de resíduos, junto ao RCD, na área de estudo 36 (município de Frederico Westphalen/RS)

Pode-se notar na figura 4, a presença de resíduos eletrônicos (TV), resíduos de poda (galhos e folhas), resíduos volumosos (cama), pneus, plásticos, resíduos metálicos, agregados, madeira, papéis (sacos de cimento), entre outros, além dos RCD. Nesses acúmulos de resíduos, a incidência de insetos e roedores podem se tornar um grande problema, envolvendo outro fator considerável, o sanitário, pois trazem riscos à saúde da população vizinha ao local de descarte.

As áreas onde ocorrem disposições irregulares servem de atrativo a vetores de interesse sanitário, os quais teriam assim acesso a proteção, alimento e água. Um exemplo disto é a prevalência do mosquito Aedes Aegypti, transmissor da Dengue, Zika, Chikungunya, que necessita de água parada para se reproduzir e que tal condição é observada na maioria dos depósitos irregulares que contem resíduos de diferentes tipologias (MAIA et al., 2012). Santos (2008) constatou 11 pontos de lançamento irregular, em Petrolina/PE, nos quais havia principalmente, blocos cerâmicos, areia, concreto e madeira. Relatou ainda que o despejo irregular em locais com solos arenosos pode ser um fator importante na contaminação do subsolo e até mesmo de águas subterrâneas. Córdoba et al. (2015) relatam que existe risco potencial de contaminação e poluição do solo e água pelo lixiviado em aterros de RCC de classe A. 
Pode ser relatado o despejo de resíduos nas áreas 14, 19, 34, 35 e 40, trazendo novos riscos ambientais, pois são Áreas de Preservação Permanente (APP), em virtude de estarem próximas a cursos d'água. Um exemplo é mostrado na figura 5, na qual a população estava dispondo seus resíduos em local que deveria ter vegetação, devido à proximidade ao córrego, o qual apresenta partes de seu leito assoreado.

Dados que corroboram os encontrados por Córdoba (2010), a partir do relato que a maioria dos descartes de RCD era realizada em cotas topográficas mais baixas, próximas a córregos e, portanto, APPs, com danos ao meio ambiente e riscos à saúde pública. Quando a disposição final dos RCD não é realizada em conformidade com a legislação vigente, pode resultar em impactos ambientais que muitas vezes são visíveis como: a degradação de áreas de preservação permanente, assoreamento de córregos e rios, obstrução de vias e logradouros públicos (FREITAS, 2009).

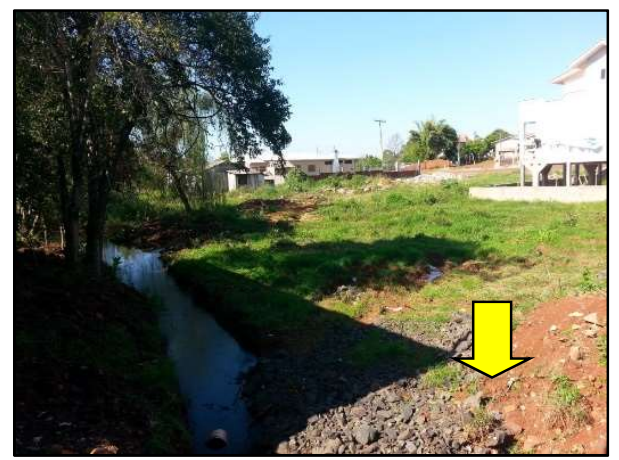

Figura 5: Assoreamento do riacho na área 40, com presença de RCD, em Frederico Westphalen, RS.

Com frequência, as áreas degradadas colocam em risco a estabilidade de encostas e comprometem a drenagem urbana. Botas-fora em vales e várzeas, depósitos irregulares ao longo dos cursos d'água são, sabidamente, fontes de constantes problemas na maioria das localidades (PINTO et al., 2005). Vendroni et al. (2008) também relatam RCD em locais inadequados, como: ruas, encostas, próximos a cursos d'água, em áreas verdes, etc.

Outro grande problema destes lançamentos clandestinos observados é a quantidade de material reutilizável perdido. Os resíduos lançados no ambiente têm uma grande capacidade de reciclagem, podendo ser utilizados para inúmeras finalidades, sem que venham a trazer malefícios ao ambiente. Os RCDs possuem grande potencial de reciclagem e reuso, por exemplo: reutilizado em estradas, drenagem, projetos de construção (RAHMAN et al., 2014); no concreto asfáltico (OSSA et al., 2016). Vedroni et al.(2008) relatam o uso de agregado de RCD, apenas na parcela mineral, para fechamento de valas na reparação de ruas e avenidas de Piracicaba/SP.

Segantini et al. (2011) afirmam que o solo-cimento é uma excelente matriz para o aproveitamento de RCD, podendo adicionar até $100 \%$, com boa qualidade de tijolos prensados. Outros exemplos de reciclagem: tijolos (SOUZA et al., 2008); concreto (LEITE, 2001); camada drenante de aterro sanitário (AFFONSO, 2005); camada de cobertura de aterro sanitário (BARROS, 2005); matéria-prima principal para confecção de tijolos e blocos (SILVA, 2014). Essas formas de aproveitamento dos resíduos são usadas em muitos municípios, também poderiam ser aplicadas em Frederico Westphalen. Assim, os principais impactos ambientais encontrados na área de estudo foram: obstrução de vias e logradores públicos; assoreamento de 
rios; acúmulo de resíduos em APP; impactos visuais; mau cheiro; proliferação de vetores; possibilidade de poluição e contaminação do solo; e possibilidade de poluição e contaminação de água superficial e subterrânea.

A questão da destinação final dos RCD é de grande importância e, segundo Wiens et al. (2006), está entre as questões mais discutidas na gestão ambiental. Este problema está associado desde a sobrecarga dos aterros sanitários, deixando ainda mais em evidência a necessidade de um correto gerenciamento desses resíduos. Há também a necessidade de novas soluções, de forma a diminuir a geração e potencializar o seu uso como matérias primas secundárias, visando solucionar os problemas de escassez de recursos naturais não renováveis (LIMA et al., 2004).

Com relação à disposição irregular, uma alternativa poderia ser a implantação de pontos para captação de pequenos volumes de RCD: ecopontos. Córdoba et al. (2011) verificaram que com presença destes locais, distribuídos de maneira equitativa por todo o município de São Carlos/SP, houve redução em número e do porte dos descartes clandestinos, sendo extremamente positivos para uma melhor gestão desse tipo de resíduo. No entanto, Córdoba et al. (2011) e Silva et al. (2012) enfatizam a necessidade de educação e a sensibilização da população para que os ecopontos sejam eficientes na captação de resíduos.

\section{CONCLUSÕES}

Há inúmeras áreas irregulares que recebem despejos de RCDs localizadas na zona urbana de Frederico Westphalen. Isso revela que, além de ser grande o desenvolvimento urbano do município, há também certo descaso perante o destino irregular dos resíduos gerados pela construção civil, fazendo com que o crescimento urbano ande na contramão da questão ambiental.

Notou-se que muitas das áreas avaliadas continuaram ativas mesmo após as três vistorias realizadas, reafirmando que há uma grande incidência de áreas não regularizadas. Porém, observa-se que muitas destas áreas são usadas para descarte provisório de resíduos e que depois do término da obra, são regularizadas. Desta forma, evidencia-se a necessidade urgente de uma legislação municipal que defina diretrizes, metas e ações e de um plano de gestão dos resíduos, e que vise orientar os gestores no sentido de minimizar as consequências dessa atividade impactante.

A caracterização quantitativa de áreas irregulares de RCDs se mostrou um indicador útil para estratégias futuras de gestão e gerenciamento de resíduos sólidos. Pode-se inferir que, devido à quantidade de áreas irregulares na cidade, há poucas ações que visem à resolução dos problemas causados pela disposição irregular.

\section{REFERÊNCIAS}

ABNT. Associação Brasileira de Normas Técnicas. NBR 10.004: Resíduos sólidos: Classificação. Rio de Janeiro: ABNT, 2004.

ABRELPE. Associação Brasileira de Empresas de Limpeza Pública e Resíduos Especiais. Panorama Nacional dos Resíduos Sólidos. São Paulo: ABRELPE, 2015.
AFFONSO, F. J. A.. Caracterização de agregados reciclados de resíduos de construção e demolição (RCD) para uso em camadas drenantes de aterros de resíduos sólidos. Dissertação (Mestrado em Engenharia Civil) - Universidade Federal do Rio de Janeiro, Rio de Janeiro, 2005. 
ANGULO, S. C.; TEIXEIRA, C. E.; CASTRO, A. L.; NOGUEIRA, T. P.. Resíduos de construção e demolição: avaliação de métodos de quantificação. Engenharia Sanitária e Ambiental, v.16, n.3, p.299-306, 2011.

ARAÚJO, J. M.; GUNTHER, W. M. R.. Caçambas coletoras de resíduos da construção e demolição no contexto do mobiliário urbano: uma questão de saúde pública e ambiental. Saúde e Sociedade, v.16, n.1, p.145-154, 2007.

BARROS, M. C.. Avaliação de um resíduo da construção civil beneficiado como material alternativo para sistema de cobertura. Dissertação (Mestrado em Engenharia Civil) Universidade Federal do Rio de Janeiro, Rio de Janeiro, 2005.

BRASIL. Lei n.12305 de 02 de agosto de 2010. Institui a Política Nacional de Resíduos Sólidos; altera a Lei 9.605 de 12 de fevereiro de 1998 e dá outras providências. Brasília: 2010.

CARNEIRO, A. P.; BRUM, I. A. S; CASSA, J. C. S.. Reciclagem de entulho para a produção de matérias de construção. Caixa Econômica Federal. EDUFBA. Salvador, 2001.

CONAMA. Conselho Nacional do Meio Ambiente. Resolução n.307 de 5 de julho de 2002. Estabelece diretrizes, critérios e procedimentos para a gestão de resíduos da construção civil. Brasília: CONAMA, 2002.

CÓRDOBA, R. E.. Estudo do sistema de gerenciamento integrado de resíduos de construção e demolição do município de São Carlos - SP. Dissertação (Mestrado em Hidráulica e Saneamento). Universidade de São Paulo, São Carlos, 2010.

CÓRDOBA, R. E.; FERREIRA, A. G.; D'ALOIA, L. G. P.; CORRÊA, T.; SCHALCH, V.. Estudo da eficiência de ecopontos no gerenciamento integrado de resíduos de construção e demolição (RCD) do município de São Carlos - SP. In: CONGRESSO BRASILEIRO DE ENGENHARIA SANITÁRIA E AMBIENTAL, 26. Anais. Porto Alegre: ABES, 2011.

CÓRDOBA, R. E.; SCHALCH, V.. Estudo do potencial de contaminação de lixiviados gerados em aterros de resíduos da construção civil por meio de simulações em colunas de lixiviação. Engenharia Civil - UM, n.51, p.23-36, 2015.

DAHLBO, H.; BACHÉR, J.; LAHTINEN, K.; JOUTTIJARVI, T.; SUOHEIMO, P.; MATTILA, T.; SIRONEN, S.; MYLLYMAA, T.; SARAMAKI, K.. Construction and demolition waste management: a holistic evaluation of environmental performance. Journal of Cleaner Production, v.107, p.333341, 2015. DOI:

http://dx.doi.org/10.1016/i.jclepro.2015.02073

DOMÍNGUEZ, A.; DOMÍNGUEZ, M. I.; IVANOVA, S.; CENTENO, M. A.; ODRIOZOLA, J. A.. Recycling of construction and demolition waste generated by building infrastructure for the production of glassy materials. Ceramics International, v.42, p.14217-15223, 2016. DOI: http://dx.doi.org/10.1016/i.ceramint.2016.06.157

FREITAS, I. M.. Os Resíduos de Construção Civil no município de Araraquara/Sp. Araraquara: 2009.

IBGE. Instituto Brasileiro de Geografia e Estatística. Censo demográfico. Rio Grande do Sul: IBGE, 2016.
LEITE, M. A.. Avaliação de propriedades mecânicas de concretos produzidos com agregados reciclados de resíduos de construção e demolição. Tese (Doutorado em Engenharia Civil) - Universidade Federal do Rio Grande do Sul, Porto Alegre, 2001.

LIMA, A. S.; CABRAL, A. E. B.. Caracterização e classificação dos resíduos de construção civil da cidade de Fortaleza (CE). Engenharia Sanitária e Ambiental, v.18, n.2, p.169-176, 2013.

LIMA, F. P., ALVES, J. D.. Reciclagem de Resíduos Sólidos da Construção e Demolição no Município de Goiânia: Benefícios Ambientais. Universidade Católica de Goiás, Goiânia, 2004.

LING, T.; POON, C.; WONG, H.. Management and recycling of waste glass in concrete products: current situations in Hong Kong. Resources, Conservation and Recycling, v.70, p.25-31, 2013. DOI:

http://dx.doi.org/10.1016/j.resconrec.2012.10.006

MAIA, E. M., GAIA, A.. Impactos Ambientais Causados pelos Resíduos de Construção Civil no Município de Belém. Monografia (Especialização em Engenharia Civil) Universidade da Amazônia, Belém, 2012.

MIRANDA, L. F. R.; ÂNGULO, S. C.; CARELI, E. D.. A reciclagem de resíduos de construção e demolição no Brasil: 1986 2008. Ambiente Construído, Porto Alegre, v.9, n.1, p.57-71, 2009.

OLIVEIRA, M. E. D.; SALES, R. J. M.; OLIVEIRA, L. A. S.; CABRAL, A. E. B.. Diagnóstico da geração e da composição dos RCD de Fortaleza - CE. Engenharia Sanitária e Ambiental, v.16, n.3, p.219-224, 2011.

OSSA, A.; GARCÍA, J. L.; BOTERO, E.. Use of recycled construction and demolition waste (CDW) aggregates: A sustainable alternative for the pavement construction industry. Journal of Cleaner Production, v.135, p.379-386, 2016. DOI: http://dx.doi.org/10.1016/i.jclepro.2016.06.088

PINTO, T. P.; GONZÁLES, J. L. R.. Manejo e gestão dos resíduos da construção civil. Brasília: CAIXA, 2005.

RAHMAN, M. A.; IMTEAZ, M.; ARULRAJAH, A.; DISFANI, M. $M$.. Suitability of recycled construction and demolition aggregates as alternative pipe backfilling materials. Journal of Cleaner Production, v.66, p.75-84, 2014. DOI: http://dx.doi.org/10.1016/j.jclepro.2013.11.005

SANTOS, A. N.. Diagnóstico da situação dos resíduos de construção e demolição (RCD) no município de Petrolina (PE). Dissertação (Mestrado em Engenharia Civil) Universidade Católica de Pernambuco, Recife, 2008.

SANTOS, E. C. G.. Aplicação de resíduos de construção e demolição reciclados ( $R C D-R$ ) em estruturas de solo reforçado. Dissertação (Mestrado em Geotecnia) Universidade de São Paulo, São Carlos, 2007.

SEGANTINI, A. A. S.; WADA, P. H.. Estudo de dosagem de tijolos de solo-cimento com adição de resíduos de construção e demolição. Acta Scientiarum. Technology, Maringá, v.33, n.2, p.179-183, 2011. DOI: http://10.4025/actascitechnol.v33i2.9377 
SILVA, M. B. L.. Novos materiais à base de resíduos de construção e domolição (RCD) e resíduos de produção de cal (RPC) para uso na construção civil. Dissertação

(Mestrado em Engenharia e Ciências dos Materiais) Universidade Federal do Paraná, Curitiba, 2014.

SILVA, V. A.; FERNANDES, A. L. T.. Cenário do gerenciamento dos resíduos de construção e demolição (RCD) em Uberaba MG. Sociedade \& Natureza, Uberlândia, v.24, n.2, p.333344, 2012.

SOUZA, M. I. B.; SEGANTINI, A. A. S.; PEREIRA, J. A.. Tijolos prensados de solo-cimento confeccionados com resíduos de concreto. Revista Brasileira de Engenharia Agrícola e Ambiental, v.12, n.2, p.205-212 2008.

VEDRONI, W. J.; CARVALHO, D.. Estudo de caso da utilização do RCD (resíduos de construção e demolição) na reparação de ruas e avenidas de Piracicaba - SP. Holos Environment, v.8, n.2, p.149-165, 2008.

WIENS, I. K.; HAMADA, J.. Gerenciamento de resíduos da construção civil: uma introdução à legislação e implantação. In: SIMPÓSIO DE ENGENHARIA DE PRODUÇÃO. Anais. Bauru: UNESP, 2006. 